\title{
The relationship between psychiatric morbidity and quality of life: interview study of Norwegian tsunami survivors 2 and 6 years post-disaster
}

Ajmal Hussain ${ }^{1,6^{*}}$, Egil Nygaard ${ }^{2,3}$, Johan Siqveland ${ }^{1,4}$ and Trond Heir ${ }^{4,5}$

\begin{abstract}
Background: The study investigated the impact of psychiatric disorders on Quality of Life (QOL) cross-sectionally and longitudinally in a group of Norwegian tourists severely exposed to the 2004 tsunami.

Methods: Sixty-two adult Norwegian tsunami survivors were interviewed face to face 2 years post-tsunami (T1) and 58 were interviewed again by telephone 6 years post-tsunami (T2). The majority (81\%) reported direct exposure to the waves, and 14 participants (23\%) lost a close family member in the tsunami. Psychiatric morbidity was measured by structured clinical interviews and QOL was assessed with WHO's Quality of Life-Bref scale. Multiple linear regression analyses were performed to assess the independent effects of psychiatric disorders on QOL 2 and 6 years after the tsunami.

Results: Psychiatric disorders, especially depression, but also PTSD and other anxiety disorders, were associated with reduced QOL. Psychiatric disorders were more strongly related to QOL at 6 years after the tsunami than at 2 years.

Conclusions: Psychiatric disorders, and especially depression, is related to reduced QOL in a disaster exposed population. Post-disaster psychiatric disorders, such as PTSD and especially depression, should be addressed properly in the aftermath of disasters.
\end{abstract}

Keywords: Depression, Natural disaster, Posttraumatic stress, Quality of life, Tsunami

\section{Background}

Research on health-related Quality of Life (QOL) has been well established over the past four decades, despite disagreements on the theoretical understanding of the concept of QOL [1]. The WHO defines QOL as individuals' perceptions of their position in life in the context of the culture and value systems in which they live and in relation to their goals, expectations, standards and concerns [2]. The QOL research has mainly focused on QOL in somatic chronic conditions [3, 4], life-threatening

\footnotetext{
* Correspondence: ajmalhus@gmail.com; ajmal.hussain@ahus.no

'Division of Mental Health Services, Akershus University Hospital, 1478 Lørenskog, Norway

${ }^{6}$ Groruddalen Community Mental Health Center, Outpatient psychiatric clinic, Division of Mental Health Services, Akershus University Hospital, P.O box 1000, 1478 Lørenskog, Norway

Full list of author information is available at the end of the article
}

diseases [5, 6], and severe psychiatric disorders, such as schizophrenia $[7,8]$, when investigating the effect of ill health on QOL. However, some studies have investigated the relationship between common psychological morbidity, i.e., anxiety and depression, and QOL [9-11], indicating that depressive and anxiety disorders may have a profound impact on health-related QOL that is independent of chronic somatic illness [12].

Major depressive disorder (MDD) is commonly associated with significant impairments in health-related QOL [13]. The Medical Outcomes Study found that persons with depression have comparable or lower QOL in regard to physical aspect, psychosocial aspect, and role functioning than those who have chronic medical conditions [14]. A meta-analytic review has also indicated poor QOL among anxiety disorder patients [15]. Further 
research has suggested that QOL impairments in anxiety disorders may be particularly prominent among patients with posttraumatic stress disorder (PTSD). This is not surprising given that PTSD results from serious traumatizing events, such as childhood abuse, rape, interpersonal violence, experience of war, captivity and torture $[16,17]$, which are likely to highly affect QOL.

However, the relationship between QOL and PTSD and other psychiatric disorders following a natural disaster has not been fully investigated and findings so far are somewhat mixed [18]. Some studies of posttraumatic stress and QOL among earthquake survivors report a relation between high levels of posttraumatic stress and poor QOL, with disaster exposure, financial loss and low levels of post-disaster support, accounting for the reduction in QOL [19-22]. In a longitudinal perspective, a negative impact of disaster on QOL was also reported among Hurricane Katrina evacuees 12 months after the storm [23], while there was no evidence for a long-term effect on QOL in a community sample eight years after an earthquake [24]. Another study found that there was no significant relation between exposure and health-related QOL in the aftermath of an oil spill disaster [25]. Few studies used structured diagnostic interviews or investigated impacts of psychiatric morbidity on QOL over time. The lack of longitudinal studies limits a cause-effect understanding of the relation between psychiatric disorders and QOL. None of the studies to date have investigated the relationship between psychiatric morbidity and different domains of QOL in a population that mostly escaped secondary disaster stressors.

In the present study, we investigated the impact of various psychiatric conditions on QOL cross-sectionally and longitudinally among Norwegian tourists severely exposed to the 2004 tsunami. In addition, we aimed to study whether there were any changes in the relationship between psychiatric morbidity and QOL from 2 to 6 years post-disaster.

\section{Method}

\section{The event}

Thailand was one of the countries affected by the 2004 Indian Ocean tsunami [26]. The province of Pang Nga was hit especially hard, with a devastating effect on the coastal community [27]. At the time of the tsunami, many Norwegians and other tourists were housed in Khao Lak in Pang Nga and experienced the horrors of the disaster [28]. Of the 84 Norwegians who perished in the disaster, 68 were housed in Khao Lak. The tsunami and its impact on tourists are described in greater detail in previous articles $[29,30]$.

\section{Study sample}

Of the 80 Norwegian survivors above 18 years known to have been present in Khao Lak at the time of the tsunami, we were able to make contact with 75 . Among them, 63 agreed to participate and were interviewed 2 years post-tsunami (T1). One participant did not respond to questions concerning quality of life at $\mathrm{T} 1$, and we could not locate four persons for the follow-up interviews 6 years post-tsunami (T2). Thus, the present study sample includes 62 participants at T1, 59 at T2 and 58 who participated in both assessments. There were no differences in age and gender between participants and those who did not participate at baseline [29]. The most common reason given for not participating was lack of time.

At the time of the first interview, none of the participants were involved in unsettled insurance cases related to the 2004 tsunami. At T1, $62.9 \%$ were married or cohabitating, $69.4 \%$ were employed, and $69.4 \%$ had higher education ( $\geq 13$ years). Only $33.9 \%$ of the participants were the sole participants in their family, $54.8 \%$ were one of two participants in their family, $4.8 \%$ were one of three participants in their family, and $6.5 \%$ were one of four participants in their family. Mean age at the time of the disaster was 40.6 years $(S D=11.3$ years), and there were 33 women $(46.8 \%)$ and 29 men. There were no significant gender differences in age, employment or education.

Twelve participants $(19.4 \%)$ reported no direct exposure to the waves, $25(40.3 \%)$ were touched or chased by the waves, and 25 (40.3\%) were caught by the waves. Twenty-six participants $(41.9 \%)$ reported tsunami-related injuries. Of these participants, 13 were hospitalized. Fourteen participants $(22.6 \%)$ reported that a close family member died in the tsunami. There were no significant gender differences in disaster exposure, injuries or loss.

At T1, $37 \%$ of the participants reported that they had sought professional help and received treatment for mental distress caused by the tsunami. Treatment mainly constituted psychotherapy alone or in combination with pharmacological treatment (mostly antidepressants).

\section{Measurements}

We used the Structured Clinical Interview for DSM-IV Axis I Disorders (SCID-I) to assess tsunami related PTSD [31]. We made a full assessment of all the PTSD criteria for all participants. To assess other psychiatric disorders, we used the Mini International Neuropsychiatric Interview (MINI), which is a brief and valid structured diagnostic interview that covers 16 axis I disorders according to DSM-IV criteria [32, 33]. With some exceptions, MINI measures current psychiatric morbidity (symptoms experienced in the previous month). We used 
the Norwegian version of the MINI 5.0.0, which has been validated in the clinical setting and shown good psychometric properties [34]. We included modules for specific phobia and somatoform pain disorder from the MINIplus [33].

QOL was measured with The World Health Organization Quality of Life-Bref scale (WHOQOL-Bref) [35, 36]. This is a self-report, abbreviated version of the WHOQOL-100. It contains 26 items divided into four domains and 2 general items. The first general item measures overall QOL, and the second general item measures overall satisfaction with own health. In the current study, we employ the terms perceived QOL and satisfaction with health, respectively, for these items. The four domains measure physical health (7 items), psychological health (6 items), social relationships (3 items), and environmental quality of life (8 items). The items are rated on a Likert scale from 1 to 5 to determine a raw item score. Domain scores are calculated by multiplying the mean of all items included within the domain by 4 , giving domain scores ranging from 4 to 20 . The transformation into scaled score is done to make the scores comparable with the WHOQOL-100. Domain scores are scaled in a positive direction (i.e., higher scores denote higher quality of life).

\section{Procedure}

All of the Norwegian tsunami survivors who had been in Khao Lak at the time of the disaster and could be located were personally contacted by telephone and invited to participate in the study. An information letter was mailed prior to the call. At T1, the participants were interviewed face to face, mostly in their homes either by the first author alone $(n=49)$ or with a co-interviewer, specialist in clinical psychology $(n=13)$. The two interviewers were trained in structured diagnostic interviewing and experienced in the administration and use of other relevant psychometric instruments. Some of the exposure variables were coded based on information extracted from the interview. In these cases, the first codings were conducted in collaboration with the co-interviewer to reach consensus. At the follow-up (T2), all of the interviews were carried out by the first author as telephone-interviews, but the collaboration with the co-interviewer was maintained. Difficult diagnostic cases were discussed between the two interviewers to reach consensus. Analyzes after T1 showed that there were moderate to high correlations between the full scale score and the two general questions. Therefore, for practical reasons, QoL was measured only by the two general items of the WHOQOL-BREF in the follow-up. With some exceptions, the questionnaires were presented before conducting the diagnostic interviews.

\section{Statistics}

Pearson Chi-square test was used to analyze grouped variables, Student's t-test was used to analyze mean differences between groups, and Pearson correlation was used to analyze bivariate relation between two continuous variables. All continuous variables were approximately normally distributed, with both skewness and kurtosis between \pm 2 ; therefore, parametric tests were used.

Major depressive disorder and dysthymic disorder were grouped together as "depressive disorders". All anxiety disorders except specific phobia and posttraumatic stress disorder (PTSD) were grouped together as "other anxiety disorders". Alcohol and illegal drug dependency and misuse were grouped together as "substance disorders".

Multiple linear regression analyses were performed to determine the independent effects of diagnoses on QOL 2 (T1) and 6 (T2) years post-tsunami. Four subdomains of QOL at T1 were used as dependent variables in four separate models. These subdomains were not measured at $\mathrm{T} 2$, and single questions concerning perceived QOL and health satisfaction were used as dependent variables at T2. The models predicting QOL and health satisfaction at T2 were rerun controlling for QOL and health satisfaction at T1. All multiple models controlled for age and gender. Confidence intervals for change in adjusted $\mathrm{R}$-square were computed by the bootstrap $\mathrm{BC}_{\mathrm{a}}$ procedure [37].

There was no missing information among the included participants on any of the analyzed variables. A significance level of .05 was used for all statistical tests. All statistical analyses were conducted using IBM SPSS Statistics, version 19.0, except bootstrap $B C_{a}$ intervals for change in adjusted R-square, which used the $\mathrm{R}$ package boot [The $\mathrm{R}$ Foundation for Statistical Computing, Vienna, Austria].

\section{Results}

The most prevalent current psychiatric disorder 2 years after the disaster was specific phobia $(n=18)$, followed by other anxiety disorders $(n=17)$, depressive disorders $(n=14)$, PTSD $(n=7)$ and substance disorders $(n=6)$. There was significant comorbidity between PTSD and both depression $\left(n=6, \chi^{2}(62,1)=17.99, P<.001\right)$ and other anxiety disorders $\left(n=5, \chi^{2}(62,1)=7.68, P=.006\right)$. None of the other diagnoses overlapped significantly. Women displayed simple phobias more often than men $\left(45.5 \%\right.$ vs. $\left.10.3 \%, \chi^{2}(62,1)=9.24, P=.002\right)$. There were no significant gender differences in depression, PTSD, other anxiety disorders or substance disorders.

\section{QOL 2 and 6 years post-disaster}

The environment was the domain of QOL with the highest mean score 2 years after the tsunami, and physical 
health was the domain with the lowest scores (Table 1). There were no significant gender differences in any domains of QOL. All domains were significantly correlated ( $r$ from .43 to .69, all with $P<.001$ ). The single questions concerning perceived QOL and health satisfaction 2 years after the tsunami were highly correlated with all four domains of QOL ( $r$ from .57 to .69 for perceived QOL and $r$ from .42 to .59 for health satisfaction, all with $P<.001$ ). Paired sample t-test indicated that there were no significant changes over time in perceived QOL or health satisfaction, as measured by a single question.

\section{Association between morbidity and domains of QOL after 2 years}

In the bivariate analyses, the four domains of QOL measured 2 years after the tsunami were significantly related to depression (Table 2). PTSD was significantly related to psychological health, social relationships, and environment, but not to physical health. Other anxiety disorders were significantly related to psychological health and social relationships, but not psychical health or environment. Specific phobias and substance disorders were not significantly related to any domains of QOL.

In the multiple regression analyses (Table 3), depression was the only psychiatric disorder that was significantly associated with the following three domains of QOL 2 years after the tsunami: physical health, psychological health, and environment. Only other anxiety disorders were significantly related to the social relationships domain. There were no other significant associations between psychiatric disorders and the four domains of QOL.

\section{Association between morbidity and QOL after 2 and 6 years}

The multiple regression analyses showed that depression was related to perceived QOL 2 and 6years after the tsunami (Table 4). PTSD and specific phobias were significantly

Table 1 Quality of life 2 years (T1) and 6 years (T2) after the tsunami

\begin{tabular}{lll}
\hline & T1 (N=62) & T2 (N=59) \\
& M (SD) & M (SD) \\
\hline Physical health $^{\mathrm{a}}$ & $12.6(1.9)$ & \\
Psychological health $^{\mathrm{a}}$ & $14.5(2.2)$ & \\
Social relationships $^{\mathrm{a}}$ & $15.3(3.1)$ & \\
Environment $^{\mathrm{a}}$ & $16.0(2.7)$ & $4.1(1.0)$ \\
Percieved quality of life $^{\mathrm{b}}$ & $4.0(0.9)$ & $3.7(1.1)$ \\
Health satisfaction $^{\mathrm{b}}$ & $3.6(1.2)$ &
\end{tabular}

Table showing quality of life scores at $\mathrm{T} 1$ and $\mathrm{T} 2$. Mean scores (M) are given, measured with the World Health Organization Quality of Life-Bref scale (WHOQOL-Bref)

${ }^{\mathrm{a} D}$ Domain scores from WHOQOL-BREF (range 4-20); these were not measured 6 years post-tsunami

${ }^{\mathrm{b}}$ Single question from WHOQOL-BREF (range 1-5) related to perceived QOL after 6 years, but not after 2 years. Both depression and PTSD, but not social phobias, remained significantly associated with perceived QOL after 6 years when controlling for perceived QOL after 2 years.

Depression was related to health satisfaction at both time points and remained significant after 6 years when controlling for health satisfaction after 2 years. None of the other psychiatric disorders were significantly related to health satisfaction at any time point in the multiple regression analyses.

Explained variance after 2 years in the regression models in Tables 4 and 5 were 51 and $22 \%$ for perceived QOL and health satisfaction, respectively, and increased to 62 and $52 \%$, respectively, 6 years postdisaster. The increase in explained variance in perceived QOL was not significant. However, the increase in explained variance in health satisfaction was significant (95\% CI of $\Delta$ adjusted $R^{2}=0.05$ to 0.56 ).

A significant number of persons with depression had lost a close family member in the tsunami ( 8 of 14 , $57.1 \%)$ compared to those without a diagnosis of depression $(6 / 48$ persons, $12.5 \%)\left(\mathrm{X}^{2}(1)=12.4, P<.001\right)$. We ran all of the multivariate analyses again while controlling for loss. We did not find any changes in results for depression in the multiple regression models.

\section{Discussion}

\section{Discussion}

We found that depression, PTSD and other anxiety disorders were associated with reduced QOL among Norwegian tsunami survivors. This is consistent with other studies of natural disaster survivors [22, 23]. In particular, depression seems to exert a broad negative effect on QOL, including overall measures of perceived QOL and health satisfaction. This finding is in agreement with many epidemiological studies [38, 39] and clinical studies [40]. However, there is no clear evidence in the literature that depression consistently has a more pronounced negative effect on QOL compared to other psychiatric disorders. It appears as though the disorder severity and its longitudinal course determine the associated reduction in QOL rather than a particular psychiatric condition per se [41]. In addition, due to the significant comorbidity between depression and PTSD in the current study, the role of PTSD may have been underestimated.

PTSD seems to have a significant negative effect on certain aspects of QOL, including psychological health, social relationships, and environment. The negative effect of PTSD or posttraumatic stress on elements of environment-related QOL is documented in previous disaster studies $[19,42]$. Still, we found these effects rather surprising, as Norwegian tourists were repatriated 
Table 2 Bivariate relations between psychiatric disorders and domains of quality of life 2 years post-tsunami $(N=62)$

\begin{tabular}{lcccc}
\hline & $\begin{array}{l}\text { Physical } \\
\text { health }\end{array}$ & $\begin{array}{l}\text { Psychological } \\
\text { health }\end{array}$ & $\begin{array}{l}\text { Social } \\
\text { relationships }\end{array}$ & Environment \\
\hline $\begin{array}{l}\text { Depressive } \\
\text { disorders }\end{array}$ & $-2.84^{* * *}$ & $-3.17^{* * *}$ & $-2.95^{* * *}$ & $-3.37^{* * *}$ \\
$\begin{array}{l}\text { Specific phobia } \\
\text { PTSD }\end{array}$ & 0.03 & -0.24 & 0.42 & -1.01 \\
$\begin{array}{l}\text { Other anxiety } \\
\text { disorders }\end{array}$ & -1.37 & $-3.25^{* * *}$ & $-4.19^{* * *}$ & $-3.99^{* * *}$ \\
$\begin{array}{l}\text { Substance } \\
\text { disorders }\end{array}$ & -0.29 & $-1.34^{*}$ & $-2.43^{* *}$ & -1.13 \\
\hline
\end{tabular}

Figures are mean differences between those with and without psychiatric disorder as tested by Student t-tests. The direction of the difference is negative thus, those without a psychiatric disorder had better quality of life than those with a psychiatric disorder

${ }^{*} P \leq .05 ;{ }^{* *} P \leq .01 ;{ }^{* * *} P \leq .001$

within a short time to stable home communities [43, 44]. Environment-related QOL includes items such as financial resources, physical safety and security, health and social care, home environment, new opportunities, opportunity for recreation, physical environment, and transportation, which are likely to be negatively affected in the aftermath of a large-scale disaster. Thus, as the majority of our population escaped most of these secondary disaster stressors, one would expect a reduced impact of disaster exposure and subsequent PTSD symptoms on environment-related QOL.

The strong negative relationship between psychiatric disorders and psychological health- and social relationshiprelated QOL was expected, as poor mental health is likely to affect these domains [45]. The adjusted model showed that depression exerted the main negative effect on psychological health, whereas other anxiety disorders had the most significant effect on social relationships. One possible explanation for this finding might be that social relations were strengthened within the families after the tsunami, especially in depressed people. A previous study of Norwegian parents who experienced the 2004 tsunami reported an increase in family care and appreciation for family values [46]. These changes remained stable 2 years after the tsunami and are likely to have occurred in our population, as many of the participants lived within a family constellation with children. Such strengthened family cohesion may have buffered the likely negative effect of depression on social relationships.

Of the psychiatric disorders, physical health-related QOL was only related to depression and remained significantly related to depression after adjustment for other psychiatric disorders. One explanation could be that the measure of physical health contains items that overlap with depression, i.e., activities in daily living, energy and fatigue, sleep, pain, and work capacity. Of note, pre-disaster physical health was generally good in the current study population and few suffered severe injury [29], which reduces the possibility of overlap between a severe somatic condition and depressive symptoms.

The prevalence of specific phobias was relatively high, but this condition was not significantly related to QOL. We have previously shown that specific phobias had little negative impact on socio-occupational functioning among Khao Lak survivors compared to depression and PTSD [29]. The psychopathological effect of specific phobias in disaster populations seems to be relatively mild, as survivors can avoid phobic exposure related to specific situations without having any major impact on their daily life activities.

We did not find a negative effect of substance disorders on QOL. Although there has been less focus on QOL in the addiction field, available evidence suggests that QOL is generally poor among active substance abusers and treatment seekers [47, 48]. However, the majority of those who were diagnosed within this cluster/group in the present study did not have a severe form of substance abuse or dependence. In addition, the use of MINI may lead to an over-diagnosis of alcohol and substance misuse in non-clinical settings.

We used the two general items from WHOQOL-BREF to assess any changes in QOL over time. We found no change in the overall score for perceived QOL and health

Table 3 Psychiatric disorders and their association with domains of quality of life 2 years post-tsunami $(N=62)$

\begin{tabular}{lllll}
\hline & Physical health & Psychological health & Social relationships & Environment \\
\hline Depressive disorders & $-3.26(-4.42,-2.10)^{* * *}$ & $-2.62(-3.93,-1.32)^{* * *}$ & $-1.69(-3.63,0.26)$ & $-2.53(-4.21,-0.84)^{* *}$ \\
Specific phobia & $0.23(-0.78,1.24)$ & $0.46(-0.67,1.59)$ & $1.10(-0.59,2.79)$ & $-0.48(-1.95,0.99)$ \\
PTSD & $1.07(-0.55,2.69)$ & $-1.02(-2.84,0.81)$ & $-2.35(-5.07,0.37)$ & $-1.92(-4.28,0.44)$ \\
Other anxiety disorders & $-0.35(-1.33,0.64)$ & $-0.67(-1.78,0.43)$ & $-1.78(-3.43,-0.13)^{*}$ & $-0.05(-1.48,1.38)$ \\
Substance disorders & $-0.55(-2.00,0.89)$ & $-0.89(-2.51,0.74)$ & $-1.80(-4.23,0.63)$ & $-0.89(-2.99,1.22)$ \\
Adjusted R & 0.33 & 0.36 & 0.28 & 0.26 \\
\hline
\end{tabular}

Multiple linear regression analyses showing various psychiatric disorders and their association with four domains of quality of life 2 years post-tsunami. Figures are unstandardized regression coefficients, with $95 \%$ confidence intervals in parenthesis. All independent variables were entered simultaneously into the models. Age and gender were controlled in all models. Neither age nor gender was a significant predictor of quality of life in any of the models. Quality of life is measured by four domains from WHOQOL-BREF

${ }^{*} P \leq .05 ;{ }^{*} P \leq .01 ;{ }^{* * *} P \leq .001$ 
Table 4 Psychiatric disorders at 2 years and their association with quality of life 2 and 6 years post-tsunami $(N=58)$

\begin{tabular}{llll}
\hline & Perceived quality of life at T1 & Perceived quality of life at T2 & Perceived quality of life at T2 controlling for T1 \\
\hline Depressive disorders & $-1.35(-1.84,-0.86)^{* * *}$ & $-1.43(-1.92,-0.95)^{* * *}$ & $-0.85(-1.41,-0.29)^{* *}$ \\
Specific phobia & $-0.11(-0.52,0.30)$ & $-0.40(-0.80,0.01)^{*}$ & $-0.35(-0.72,0.02)$ \\
PTSD & $-0.44(-1.16,0.28)$ & $-0.85(-1.55,-0.14)^{*}$ & $-0.66(-1.31,-0.01)^{*}$ \\
Other anxiety disorders & $-0.04(-0.46,0.69)$ & $-0.13(-0.55,0.29)$ & $-0.12(-0.49,0.26)$ \\
Substance disorders & $-0.08(-0.73,0.57)$ & $-0.14(-0.78,0.50)$ & $-0.11(-0.69,0.48)$ \\
Perceived quality of life at T1 & & & $-0.43(-0.69,-0.18)^{* * *}$ \\
Adjusted R & 0.51 & 0.62 & 0.69 \\
\hline
\end{tabular}

Multiple linear regression analyses of psychiatric disorders at 2 years association with perceived quality of life 2 (T1) and 6 years (T2) post-tsunami. Figures are unstandardized regression coefficients, with $95 \%$ confidence intervals in parenthesis. All independent variables were entered simultaneously into the models. Age and gender were controlled in all models. Gender and age were not significant predictors of perceived quality of life in any of the models. Perceived quality of life is here measured with a single question from WHOQOL-BREF: "How would you rate your quality of life?"

${ }^{*} P \leq .05 ;$ ** $P \leq .01 ;{ }^{* * *} P \leq .001$

satisfaction from 2 years to 6 years after the tsunami. However, we found that psychiatric morbidity showed an overall increase in explained variance for both perceived QOL (51 to $62 \%$ ) and health satisfaction (22 to $52 \%$ ) from 2 to 6 years. All of the predictors were measured 2 years after the tsunami and more than 3 years before the last measure of QOL. Thus, we expected a decrease in the relation between psychiatric morbidity and QOL over time, as posttraumatic stress and other psychopathology tend to decrease with time after disasters $[49,50]$. In addition, a correlation tends to weaken as the time between the measurements increases. One interpretation of the present finding may be that individuals who recover experience an increase in QOL, whereas individuals who do not recover experience either an increase in symptom level and subsequent poorer QOL or merely a negative change in perception of QOL with time [51, 52]. We cannot rule out that other variables, i.e. changes in socioeconomic status and aging process, may have contributed to strengthen the relationship between psychiatric morbidity and QOL over time. Another finding that supports the idea that changes occurred from 2 to 6 years post-disaster is that both PTSD and depression showed a reinforced negative relation to perceived QOL from $\mathrm{T} 1$ to T2. A similar change also occurred between depression and the construct of health satisfaction in QOL.

We believe that development of chronic mental illness may lead to a worsening of QOL due to deterioration of social relations, inappropriate use of own personal resources, apostasy from work, and increasing social isolation [52]. A study of earthquake survivors showed that QOL was worsened with time among those who received less relief support in the aftermath of disaster [53]. This may be opposed to chronic somatic conditions, for which many persons successfully adapt to symptoms, maintain social relations and are able to focus on their personal resources [54]. However, some studies also indicate that long-lasting depression may have debilitating effects on work and psychosocial functioning even after significant reduction in depressive symptoms [39, 54, 55]. As work and psychosocial functioning are closely linked to QOL, we cannot rule out the occurrence of the latter among some of the persons in the population.

Table 5 Psychiatric disorders at 2 years and their association with satisfaction with health 2 and 6 years post-tsunami ( $N=58$ )

\begin{tabular}{llll}
\hline & Health satisfaction at T1 & Health satisfaction at T2 & Health satisfaction at T2 controlling for T1 \\
\hline Depressive disorders & $-1.13(-1.94,-0.31)^{* *}$ & $-1.89(-2.48,-1.31)^{* * *}$ & $-1.51(-2.08,-0.95)^{* * *}$ \\
Specific phobia & $-0.35(-1.02,0.33)$ & $-0.24(-0.73,0.25)$ & $-0.12(-0.56,0.32)$ \\
PTSD & $-0.12(-1.30,1.07)$ & $0.30(-0.55,1.15)$ & $0.34(-0.42,1.10)$ \\
Other anxiety disorders & $-0.16(-0.86,0.54)$ & $-0.26(-0.76,0.24)$ & $-0.20(-0.65,0.25)$ \\
Substance disorders & $0.33(-0.75,1.41)$ & $-0.04(-0.81,0.73)$ & $-0.15(-0.84,0.54)$ \\
Health satisfaction at T1 & & & $-0.34(-0.52,-0.15)^{* * *}$ \\
Adjusted R & 0.22 & 0.52 & 0.62
\end{tabular}

Multiple linear regression analyses of psychiatric disorders at 2 years association with satisfaction with health 2 (T1) and 6 years (T2) post-tsunami. Figures are unstandardized regression coefficients, with $95 \%$ confidence intervals in parenthesis. All independent variables were entered simultaneously into the models. Age and gender were controlled in all models. Gender was not a significant predictor of Health satisfaction in any of the models. Age was significantly related to Health satisfaction at $\mathrm{T} 1(B=-0.03,95 \% C l=-0.05$ to $0.00, p=.05)$, but was not significant in any of the other models. Health satisfaction is here measured with a single question from WHOQOL-BREF: "How satisfied are you with your health?"

${ }^{*} P \leq .05 ;{ }^{* *} P \leq .01 ;{ }^{* * *} U S P \leq .001$ 


\section{Methodological considerations}

There are some limitations in the study. The small sample size yields low power for many of the analyzes. This suggests that caution must be made regarding the conclusions. In addition, the relatively small sample size limited detailed analyses i.e. of all the individual psychiatric disorders and other subgroups, as the results would have been more uncertain and difficult to interpret. Although we achieved a high response rate, there is still possibility of selection bias, as the main reason for not participating was lack of time, meaning that non-participants had a busy life, which may indicate a good quality of life and a good mental health. However, it is unclear how this assumption may have affected our results. The majority of the sample had at least one other family member experience the trauma with them which may have facilitated a feeling of strengthened social support and thereby influenced the results.

Telephone interviews were conducted in the 6-year follow-up compared to face-to-face interviews in the 2-year study, which could have affected the results. However, telephone interviews are often used in epidemiological research and are a valid method of assessing structured information such as axis I psychiatric disorders [56].

Generally, the present findings may be limited to populations that experience traumatic events with a sudden impact and relatively brief exposure and may not be applicable to other populations that are exposed to chronic stressors. One may also argue that this sample of Norwegians, having the possibility to spend their Christmas holiday abroad, may represent a more privileged sub-population of the Norwegian population. It is previously described that The Norwegian tourist population that experienced the tsunami did not differ from the general Norwegian population with regard to employment and marital status [57], though they had a higher than average education level and family constellation with children, which may indicate higher than average levels of socioeconomic status.

It is suggested that the prevalence of psychopathology documented in studies after natural disasters is generally lower than that documented after man-made disasters [50]. However, in studies of natural disasters it is more difficult to explicitly identify groups of persons who can be considered direct victims. Natural disasters often affect large areas and the study samples predominantly include persons from a broader area affected by the disaster. When studying persons who were in the more heavily affected areas at time of the disaster, like our population, higher prevalence's of psychopathology are reported $[58,59]$.

The measure of QOL at T2 was restricted to perceived quality of life and health satisfaction measured with two single questions. This limits a thorough understanding of changes observed in the relation between psychiatric morbidity and QOL.

There are several strengths in the study. We achieved a relatively high response rate at $\mathrm{T} 1$ and the attrition rate between $\mathrm{T} 1$ and $\mathrm{T} 2$ was low, reducing the risk for bias. We used structured clinical interviews to detect a broad range of psychiatric conditions rather than covering a few disorders through self-reported questionnaires. We asked additional questions for the most relevant psychiatric disorders in order to follow the trajectories of these conditions. The study population was rather homogeneous due to the nature of the travel regarding work, family, finance, and physical and mental health. The relatively fast evacuation of the Norwegian tourists reduced the impact of secondary disaster stressors, limiting the impact of trauma to the primary tsunami experience. Finally, regardless of impairment level, the present sample received affordable and easily accessible medical and psychiatric care as well as ample community support $[60,61]$.

\section{Conclusions}

In the current study of Norwegian tsunami survivors, we found that both depression and PTSD were negatively correlated with QOL both cross-sectionally and longitudinally. Psychiatric disorders, especially depression, must be addressed properly in the aftermath of disasters, as they have a continuously negative effect on QOL.

\section{Abbreviations \\ $\mathrm{Cl}$, Confidence interval; DSM-IV, Diagnostic statistical manual of mental disorders, fourth edition; M, Mean; MDD, Major depressive disorder; MINI, Mini international neuropsychiatric interview; PTSD, Post-traumatic stress disorder; QOL, Quality of life; SCID-I, Structured clinical interview for DSM-IV, axis I disorders; SD, Standard deviation; WHO, World Health Organization; WHOQOL-Bref, The World Health Organization Quality of Life-Bref scale}

\section{Acknowledgements \\ The authors thank the many staff members at Norwegian Centre for Traumatic Stress Studies, and especially psychologist specialist Pål Kristensen and professor Lars Weisæth for their contribution to the preparation of the study. We also like to thank Dr. Mary Kalfoss at Diakonova University College Oslo, Norway for her useful advice on WHOQOL-Bref.}

\section{Availability of data and materials}

Public availability of data would compromise the respondents' privacy. According to the approval from The Regional Committee for Medical Research Ethics and The Norwegian Data Inspectorate, the data are to be stored properly and in line with the Norwegian Law of privacy protection. However, anonymized data are freely available to interested researchers upon request, pending ethical approval from the Ethics committee. Interested researchers can contact project leader Prof. Trond Heir (trond.heir@medisin.no) with requests for the data underlying these findings.

\section{Authors' contributions}

All authors contributed in conception, design, and interpretation of data. $\mathrm{AH}$ collected data and drafted the manuscript. EN performed the statistical analysis and revised the manuscript. JS contributed in the revision of the manuscript. TH participated in the revision of the manuscript and was the 
general supervisor for the project. All authors read and approved the final manuscript.

\section{Competing interests}

The authors declare that they have no competing interests.

\section{Consent for publication}

Not applicable.

\section{Ethics}

The Regional Committee for Medical Research Ethics - South East (REC South East), approved the study. We obtained written informed consent from all study participants before the interview began.

\section{Financial support}

The first wave of data collection 2 years post disaster (T1) was funded by The Research Council of Norway (grant number 175269). The Research Council had no further role in study design, data collection and analysis, or in the decision to submit the manuscript for publication.

\section{Author details}

${ }^{1}$ Division of Mental Health Services, Akershus University Hospital, 1478 Lørenskog, Norway. ${ }^{2}$ Department of Psychology, University of Oslo, P.O box 1094, Blindern, 0317 Oslo, Norway. ${ }^{3}$ Center for Child and Adolescent Mental Health, Eastern and Southern Norway (RBUP), P.O. box 4623, Nydalen, 0405 Oslo, Norway. ${ }^{4}$ Institute of Clinical of Medicine, University of Oslo, P.O box 1078, Blindern, 0316 Oslo, Norway. ${ }^{5}$ Norwegian Centre for Violence and Traumatic Stress Studies, University of Oslo, P.O box 181, Nydalen, 0409 Oslo, Norway. ${ }^{6}$ Groruddalen Community Mental Health Center, Outpatient psychiatric clinic, Division of Mental Health Services, Akershus University Hospital, P.O box 1000, 1478 Lørenskog, Norway.

Received: 3 May 2015 Accepted: 16 May 2016

Published online: 31 May 2016

\section{References}

1. Sirgy MJ, Michalos AC, Ferriss AL, Easterlin RA, Pavot W, Patrick D. The quality of life (QOL) research movement: past, present and future. Soc Indic Res. 2006;76:343-466.

2. WHO QoL Group. The development of the World Health Organization Quality of Life Assessment Instrument (the WHOQoL). In: Orley J, Kuyken W, editors. Quality of Life Assessment: International Perspectives. Heidleberg: Springer Verlag; 1994. p. 44

3. Centers for Disease Control and Prevention, Atlanta, USA. Health related quality of life - Key findings. [www.cdc.gov/chronicdisease/about/programs. htm]. Accessed 27 Apr 2016.

4. Zhang X, Norris SL, Chowdhury FM, Gregg EW, Zhang P. The effects of interventions on health-related quality of life among persons with diabetes: a systematic review. Med Care. 2007;45:820-34.

5. Bloom JR, Petersen DM, Kang SH. Multi-dimensional quality of life among long-term (5+ years) adult cancer survivors. Psychooncology. 2007;16:691-706.

6. Richardson LC, Wingo PA, Zack MM, Zahran HS, King JB. Health-related quality of life (HRQOL) in cancer survivors between 20 and 64: populationbased estimates from the Behavioral Risk Factor Surveillance System (BRFSS). Cancer. 2008;112:1380-9.

7. Staring $A B$, Van der Gaag M, Van den Berge M, Duivenvoorden HJ, Mulder $\mathrm{CL}$. Stigma moderates the associations of insight with depressed mood, low self-esteem, and low quality of life in patients with schizophrenia spectrum disorders. Schizophr Res. 2009;115:363-9.

8. Yamauchi K, Aki H, Tomotake M, Iga J, Numata S, Motoki I, et al. Predictors of subjective and objective quality of life in outpatients with schizophrenia. Psychiat Clin Neuros. 2008;62:404-11.

9. Brenes GA. Anxiety, depression, and quality of life in primary care patients Prim Care Companion J Clin Psychiatry. 2007;9:437-43.

10. Katschnig H, Krautgartner M, Schrank B, Angermeyer MC. Quality of life in depression. In: Katschnig H, Freeman H, Sartorius N, editors. Quality of Life in Mental Disorders. 2nd ed. Chichester: Wiley; 2006. p. 129-40.

11. Mendlowicz MV, Stein MB. Quality of life in individuals with anxiety disorders. Am J Psychiatry. 2000;15:669-82.
12. Surtees $P G$, Wainwright NW, Khaw KT, Day NE. Functional health status, chronic medical conditions and disorders of mood. Brit J Psychiatry. 2003; 183:299-303.

13. Kessler RC, Berglund $P$, Demler $O$, Jin R, Koretz D, Merikangas KR, et al. The epidemiology of major depressive disorder: results from the National Comorbidity Survey Replication (NCS-R). JAMA. 2003;289:3095-105

14. Wells KB, Stewart A, Hays RD, Burnam MA, Rogers W, Daniels M, et al. The functioning and well-being of depressed patients. Results from the Medical Outcomes Study. JAMA. 1989;262:914-9.

15. Olatunji BO, Cisler JM, Tolin DF. Quality of life in the anxiety disorders: a meta-analytic review. Clin Psychol Rev. 2007;27:572-81.

16. American Psychiatric Association. Practice guidelines for Acute Stress Disorder and Post-traumatic Stress Disorder. Washington DC: American Psychiatric Association; 2004.

17. Darves-Bornoz JM, Alonso J, de Girolamo G, de Graaf R, Haro JM, KovessMasfety V, ESEMeD/MHEDEA 2000 Investigators, et al. Main traumatic events in Europe: PTSD in the European study of the epidemiology of mental disorders survey. J Trauma Stress. 2008;21:455-62.

18. Goenjian AK, Roussos A, Steinberg AM, Sotiropoulou C, Walling D, Kakaki M, et al. Longitudinal study of PTSD, depression, and quality of life among adolescents after the Parnitha earthquake. J Affect Disord. 2011;133:509-15.

19. Ceyhan E, Ceyhan AA. Earthquake survivors' quality of life and academic achievement six years after the earthquakes in Marmara. Turkey Disasters. 2007;31:516-29.

20. Chou FH, Chou P, Lin C, Su T, Ou-Yang WC, Chien IC, et al. The relationship between quality of life and psychiatric impairment for a Taiwanese community post-earthquake. Qual Life Res. 2004;13:1089-97.

21. Tsai KY, Chou P, Chou FH, Su TT, Lin SC, Lu MK, et al. Three-year follow-up study of the relationship between posttraumatic stress symptoms and quality of life among earthquake survivors in Yu-Chi, Taiwan. J Psychiatr Res. 2007;41:90-6

22. Wang X, Gao L, Zhang H, Zhao C, Shen Y, Shinfuku N. Post-earthquake quality of life and psychological well-being: longitudinal evaluation in a rural community sample in northern China. Psychiat Clin Neuros. 2000; 54:427-33.

23. LaJoie AS, Sprang G, McKinney WP. Long-term effects of Hurricane Katrina on the psychological well-being of evacuees. Disasters. 2010;34:1031-44.

24. Priebe S, Marchi F, Bini L, Flego M, Costa A, Galeazzi G. Mental disorders, psychological symptoms and quality of life 8 years after an earthquake: findings from a community sample in Italy. Soc Psych Psych Epid. 2011;46:615-21.

25. Carrasco JM, Pérez-Gómez B, García-Mendizábal MJ, Lope V, Aragonés N, Forjaz MJ, et al. Health-related quality of life and mental health in the medium-term aftermath of the Prestige oil spill in Galiza (Spain): a crosssectional study. BMC Public Health. 2007:7:245.

26. van Griensven F, Chakkraband ML, Thienkrua W, Pengjuntr W, Lopes CB, Cardozo B, et al. Mental health problems among adults in tsunami-affected areas in southern Thailand. JAMA. 2006;296:537-48.

27. Paton D, Gregg CE, Houghton BF, Lachman R, Lachman J, Johnston DM, et al. The impact of the 2004 tsunami on coastal Thai communities: assessing adaptive capacity. Disasters. 2008:32:106-19.

28. Heir T, Weisaeth L. Acute disaster exposure and mental health complaints of Norwegian tsunami survivors six months post disaster. Psychiatry. 2008; $71: 266-76$.

29. Hussain A, Weisaeth L, Heir T. Psychiatric disorders and functional impairment among disaster victims after exposure to a natural disaster: a population based study. J Affect Disord. 2011;128:135-41.

30. Heir T, Rosendal S, Bergh-Johannesson K, Michel PO, Mortensen EL, Weisaeth $L$, et al. Tsunami-affected Scandinavian tourists: Disaster exposure and post-traumatic stress symptoms. Nord J Psychiatry. 2011; 65:9-15.

31. First MB, Spitzer RL, Gibbon M, Williams JB. Structured Clinical Interview for DSM-IV Axis I Disorders-Patient Edition (SCID I/P, version 2.0). Biometrics Research; New York State Psychiatric Institute; 1995.

32. Sheehan DV, Lecrubier $Y$, Sheehan KH, Amorim P, Janavs J, Weiller $E$, et al. The validity of the Mini International Neuropsychiatric Interview (M.I.N.I.) according to the SCID-P and its reliability. Eur Psychiatry. 1997:12:232-41. 
33. Sheehan DV, Lecrubier Y, Sheehan KH, Janavs J, Weiller E, Keskiner A. The Mini International Neuropsychiatric Interview (M.I.N.I.): the development and validation of a structured diagnostic psychiatric interview for DSM-IV and ICD-10. J Clin Psychiatry. 1998;59 suppl 20:22-33.

34. Mordal J, Gundersen O, Bramness JG. Norwegian version of the MiniInternational Neuropsychiatric Interview: feasibility, acceptability and test-retest reliability in an acute psychiatric ward. Eur Psychiatry. 2010; 25:172-7.

35. Skevington SM, Lotfy M, O'Connell KA. The World Health Organization's WHOQOL-BREF quality of life assessment: Psychometric properties and results of the international field trial. A Report from the WHOQOL Group. Qual Life Res. 2004;13:299-310.

36. WHO QoL Group. Development of the World Health Organization WHOQOL-BREF quality of life assessment. Psychol Med. 1998;28:551-8.

37. Efron B, Tibshirani RJ. An Introduction to the Bootstrap. New York: Chapman and Hall; 1993.

38. de Almeida Fleck MP, Simon G, Herrman H, Bushnell D, Martin M, Patrick D. Major depression and its correlates in primary care settings in six countries : 9-month follow-up study. Brit J Psychiatry. 2005;186:41-7.

39. Rhebergen D, Beekman AT, de Graaf R, Nolen WA, Spijker J, Hoogendijk WJ, et al. Trajectories of recovery of social and physical functioning in major depression, dysthymic disorder and double depression: a 3-year follow-up. J Affect Disord. 2010;124:148-56.

40. Fekadu A, Wooderson SC, Markopoulo K, Donaldson C, Papadopoulos A, Cleare AJ. What happens to patients with treatment-resistant depression? A systematic review of medium to long term outcome studies. J Affect Disord. 2009;116:4-11.

41. Saarni SI, Suvisaari J, Sintonen H, Pirkola S, Koskinen S, Aromaa A, et al. Impact of psychiatric disorders on health-related quality of life: general population survey. Brit J Psychiatry. 2007;190:326-32.

42. Wu HC, Chou P, Chou FH, Su CY, Tsai KY, Ou-Yang WC, et al. Survey of quality of life and related risk factors for a Taiwanese village population 3 years post-earthquake. Aust NZ J Psychiatry. 2006:40:355-61.

43. Heir T, Sandvik L, Weisaeth L. Hallmarks of posttraumatic stress: Symptom z-scores in a Tsunami affected tourist population. Psychopathology. 2009; 42:157-64.

44. Hussain A, Weisaeth L, Heir T. Posttraumatic stress and symptom improvement in Norwegian tourists exposed to the 2004 tsunami - a longitudinal study. BMC Psychiatry. 2013;13:232.

45. Kilian $\mathrm{R}$, Matschinger $\mathrm{H}$, Angermeyer MC. The impact of chronic illness on subjective quality of life: a comparison between general population and hospital inpatients with somatic and psychiatric diseases. Clin Psychol Psychot. 2001;8:206-13.

46. Lindgaard $C$, Iglebæk $T$, Jensen TK. Changes in family functioning in the aftermath of a natural disaster - the 2004 Tsunami in South East Asia. J Loss Trauma. 2009;14:101-16.

47. Laudet $A B$. The case for considering quality of life in addiction research and clinical practice. Addict Sci Clin Pract. 2011;6:44-55.

48. Smith KW, Larson MJ. Quality of life assessments by adult substance abusers receiving publicly funded treatment in Massachusetts. Am J Drug Alcohol Ab. 2003;29:323-35.

49. Carr VJ, Lewin TJ, Kenardy JA, Webster RA, Hazell PL, Carter GL, et al. Psychosocial sequelae of the 1989 Newcastle earthquake: III. Role of vulnerability factors in post-disaster morbidity. Psychol Med. 1997;27:179-90.

50. Norris FH, Friedman MJ, Watson PJ, Byrne C, Diaz E, Kaniasty K. 60,000 disaster victims speak: Part I. An empirical review of the literature, 1981-2001. Psychiatry. 2002:65:207-39.

51. Allison PJ, Locker D, Feine JS. Quality of life: a dynamic construct. Soc Sci Med. 1997:45:221-30.

52. Katschnig H. Quality of life in mental disorders: challenges for research and clinical practice. World Psychiatry. 2006;5:139-45.

53. Wang X, Gao L, Shinfuku N, Zhang H, Zhao C, Shen Y. Longitudinal study of earthquake-related PTSD in a randomly selected community sample in north China. Am J Psychiatry. 2000;157:1260-6.

54. Adler DA, McLaughlin TJ, Rogers WH, Chang H, Lapitsky L, Lerner D. Job performance deficits due to depression. Am J Psychiatry. 2006;163:1569-76.

55. Hammar A, Ardal G. Cognitive functioning in major depression-a summary. Front Hum Neurosci. 2009; doi:10.3389/neuro.09.026.2009.

56. Rhode P, Lewinsohn PM, Seeley JR. Comparability of telephone and face-toface interviews in assessing Axis I and II disorders. Am J Psychiatry. 1997;154 1593-98.
57. Heir T, Piatigorsky A, Weisaeth L. Longitudinal changes in recalled perceived life threat after a natural disaster. Brit J Psychiatry. 2009:194:510-14.

58. Najarian L, Goenjian AK, Pelcovitz D, Mandel F, Najarian B. The effect of relocation after a natural disaster. J Trauma Stress. 2001;14:511-26.

59. Suar D, Mandal MK, Khuntia R. Supercyclone in Orissa: an assessment of psychological status of survivors. J Trauma Stress. 2002;15:313-19.

60. Hjemdal OK. "Follow-up of disaster victims. The role of general practitioners", (In Norwegian, English summary). Resource document. Oslo: Norwegian Centre for Violence and Traumatic Stress Studies; 2007. Retrieved from [https://www.nkvts.no/content/uploads/2015/08/tsunamien_ fastlegerapport2.pdf], Accessed 27 May 2016.

61. Michel PO, Rosendal S, Weisaeth L, Heir T. Use of and satisfaction with support received among survivors from three Scandinavian countries after the 2004 Southeast Asian tsunami. Eur Psychiatry. 2011;26:436-40.

\section{Submit your next manuscript to BioMed Central and we will help you at every step:}

- We accept pre-submission inquiries

- Our selector tool helps you to find the most relevant journal

- We provide round the clock customer support

- Convenient online submission

- Thorough peer review

- Inclusion in PubMed and all major indexing services

- Maximum visibility for your research

Submit your manuscript at www.biomedcentral.com/submit

) Biomed Central 